\title{
Separation and preconcentration followed by ICP-OES and ICP-MS determination of precious metals using silica gel chemically modified with dithiocarbamate groups
}

Vladimir N. Losev, ${ }^{\text {a }}$ VictoriyaV. Parfenova, ${ }^{\text {a }}$ EvgeneyV. Elsufev, ${ }^{\text {a }}$ Elena V.Borodina, ${ }^{\text {a }}$ Segey I. Metelitsa, ${ }^{\mathrm{a}}$ Anatoliy K.Trofimchuk ${ }^{\mathrm{b}}$

${ }^{a}$ Scientific research engineering center "Kristall”, Siberian Federal University, Krasnoyarsk 660041, Russia.

${ }^{b}$ Taras Shevchenko National University of Kyiv, Kyiv 01033, Ukraine

\begin{abstract}
Silica gel chemically modified with dithiocarbamate groups (DTCS) was used for separation and preconcentration of precious metals and their subsequent determination in geological samples and their processing products by inductively coupled plasma optical emission spectrometry and inductively coupled plasma mass-spectrometry. DTCS was characterized by TGA/DSC, FT-IR, and CHNS-analysis. DTCS quantitatively extracted $\mathrm{Au}^{3+}, \mathrm{Pd}^{2+}, \mathrm{Pt}^{2+}, \mathrm{Pt}^{4+}$ at $20^{\circ} \mathrm{C}$ from $0.5-4.0 \mathrm{M}$ $\mathrm{HCl}$ media and $\mathrm{Rh}^{3+}, \mathrm{Ir}^{4+}, \mathrm{Ru}^{4+}, \mathrm{Os}^{4+}$ at $95^{\circ} \mathrm{C}$ in the presence of $0.025 \mathrm{M} \mathrm{SnCl}_{2}$. Two-column procedure was proposed to separate precious metals from matrix components and to separate kinetically inert precious metals from kinetically labile ones.
\end{abstract}

Keywords: precious metals, solid-phase extraction, chemically modified silica gel, ICP-OES, ICP-MS

\section{Introduction}

Inductively coupled plasma optical emission spectrometry (ICP-OES) and inductively coupled plasma mass spectrometry (ICP-MS) are the most common methods for determination of trace precious metals in complex geological samples. To improve the selectivity and sensitivity of determination, solid-phase extraction (SPE) of precious metals is widely used prior to their subsequent ICP-OES and ICP-MS determination [1-4]. The main conditions for development of SPE procedure before ICP-OES and ICP-MS determination are quantitative recovery of the analytes from solutions and their quantitative elution from the adsorbent surface.

A number of adsorbents have been proposed for precocentration of precious metals [5,6]; they differ both in matrices and nature of functional groups. 
Chemically modified silica gels (CMS) are the most promising among the many adsorbents proposed for SPE of precious metals [7-9]. Due to silicon oxide matrix these adsorbents do not swell in aqueous solutions, and possess enough mechanical strength and hydrolytic stability in solutions.

CMS are characterized by good kinetic properties because of the surface arrangement of functional groups. Various silica gels chemically modified with mercapto groups [10,11], disulfide groups [12], thiourea and its derivatives groups [13,14] have been proposed for precious metal ions SPE.

A significant advantage of sulfur-containing silica based adsorbents is their ability to extract precious metals from dilute (1-4M) solutions of hydrochloric acid, which allows their separation from non-ferrous and other related metals, which form complexes with sulfurcontaining groups in weakly acidic, neutral or weakly alkaline media.

Among sulfur-containing organic reagents special attention have been paid to dithiocarbamates - compounds, that contain carbodithion group comprised of thiol and thione sulfur and linked with nitrogen atom. Dithiocarbamates were extensively used for liquid extraction of precious metals [15]. Polymer based adsorbent with dithiocabamate groups has been proposed for preconcentration and determination of $\mathrm{Au}, \mathrm{Ag}, \mathrm{Pd}$, and $\mathrm{Pt}$ in the geological certified reference material [16]. Most studies are devoted to the SPE of $\mathrm{Au}^{3+}, \mathrm{Pd}^{2+}$, and $\mathrm{Pt}^{4+}$, that are kinetically labile in the reactions of ligand substitution; adsorption of kinetically inert $\mathrm{Rh}^{3+}$, $\mathrm{Ir}^{4+}, \mathrm{Ru}^{4+}, \mathrm{Os}^{4+}$ remains without attention as a rule.

The aim of the present work was to investigate solid-phase extraction of precious metal ions, to separate them from non-ferrous and other related metals, and to separate kinetically inert precious metal ions from kinetically labile ones using silica gel chemically modified with dithiocarbamate groups (DTCS) and to develop SPE-ICP-OES and SPE-ICP-MS procedures for determination of precious metals in geological samples and their processing products.

\section{Materials and Methods}

\section{Instrumentation}

Metal distribution was monitored by ICP-OES analyses of an aqueous phase using iCAP 6500 Duo instrument (Thermo Scientific, USA). The ICP-OES operational conditions are represented in Table 1. The most intense emission lines of the elements shown in Table 1 were used for ICPOES determination of precious metals in solutions, as well as in solutions after desorption of platinum metals from the surface of adsorbents.

An XSeriesII inductively coupled plasma mass spectrometer (Thermo Scientific, USA) was used for determination of low concentrations of gold and platinum group metals in eluates. 
The ICP-MS operational conditions are listed in Table 2. ICP-MS determination of precious metals in desorbing solutions was carried out using their isotopes that are free from the influence of isotopes of other platinum metals.

Muffle furnace SNOL 6/10-V (TECHNOTHERM, Russia) was used for the geological samples firing.

The $\mathrm{pH}$ of the solutions was measured using a SevenMulti ion meter (Mettler-Toledo, Switzerland).

A Masterflex L/S peristaltic pump (Cole-Parmer Instruments Company, USA) was used for pumping fluids through the mini-column packed with an adsorbent. Glass mini-column or thermostated glass mini-column (i.d. of $3 \mathrm{~mm}$, height of $10 \mathrm{~cm}$ ) was used for preconcentration of metal ions in dynamic mode.

The concentration of dithiocarbamate groups on the silica surface was determined by elemental analysis using HCNS-0 EA 1112 analyzer (Flash, USA).

DTCS was analyzed by Fourier-transform infrared spectroscopy (FT-IR) using spectrometer Nicolet 380 with Smart Orbit accessories (Thermo Scientific, USA) in the wavelength range of $4000-400 \mathrm{~cm}^{-1}$ with $4 \mathrm{~cm}^{-1}$ spectral resolution. The samples were mixed with potassium bromide of spectral grade.

Thermal analysis was performed by the simultaneous STA 449 C Jupiter thermal analyzer (Netzsch, Germany) combined with an FT-IR spectrometer Nicolet 380 (Thermo Scientific, USA) and with the TGA/FT-IR interface. This setup allows one to receive the differential scanning calorimetry (DSC) and thermogravimetric analysis (TGA) data simultaneously, and the released gas phase composition. The temporal dependence of the optical density for each of the released gases was obtained from IR spectra. The sample was placed into a platinum crucible and heated within the temperature range of $30-760^{\circ} \mathrm{C}$.

\section{Reagents}

$\mathrm{AgNO}_{3}, \quad \mathrm{H}\left[\mathrm{AuCl}_{4}\right] \cdot 4 \mathrm{H}_{2} \mathrm{O}, \quad \mathrm{PdCl}_{2}, \quad \mathrm{~K}_{2}\left[\mathrm{PtCl}_{6}\right] \cdot 6 \mathrm{H}_{2} \mathrm{O}, \quad \mathrm{H}_{3}\left[\mathrm{RhCl}_{6}\right], \quad \mathrm{Na}_{2}\left[\mathrm{IrCl}_{6}\right], \quad \mathrm{K}_{2}\left[\mathrm{RuCl}_{6}\right]$, $\mathrm{K}_{2}\left[\mathrm{OsCl}_{6}\right] \cdot$ reagent grade were purchased from JSC “Aurat” (Russia).

Stock solutions of $\mathrm{Ag}^{+}, \mathrm{Au}^{3+}, \mathrm{Pd}^{2+}, \mathrm{Pt}^{4+}, \mathrm{Rh}^{3+}, \mathrm{Ir}^{4+}, \mathrm{Ru}^{4+}, \mathrm{Os}^{4+}\left(1.0 \mathrm{mg} \mathrm{mL}{ }^{-1}\right)$ were prepared by dissolving the corresponding salts in $2.0 \mathrm{M} \mathrm{HCl}$.

Solutions of $\mathrm{Na}^{+}, \mathrm{K}^{+}, \mathrm{Ca}^{2+}, \mathrm{Mg}^{2+}, \mathrm{Fe}^{3+}, \mathrm{Al}^{3+}, \mathrm{Cu}^{2+}, \mathrm{Pb}^{2+}, \mathrm{Zn}^{2+}, \mathrm{Mn}^{2+}, \mathrm{Ni}^{2+}, \mathrm{Co}^{2+}$, and $\mathrm{Fe}^{2+}$ were prepared by dissolving the corresponding salts (Chemreaktivsnab, Russia) in $0.1 \mathrm{M} \mathrm{HCl}$.

ICP-MCS-12 (Au, Pd, Rh, Ir, Pt, and Ru), ICP-MCS-10 (Al, Ba, Be, Co, Cu, Fe, and V), ICP-MCS-8 (Al, Ca, Cr, Li, Ni, K, Na, and Sr), ICP-MCS-2 (Ba, Ca, Co, Fe, Mg, Ni, Si, and V), ICP-MCS-As, Be, B, Cd, Pb, Mn, Se, and Zn), 10-51-1 (Ag), 10-70-2 (Os) were used as 
calibration standards for ICP-OES and ICP-MS. The standards were purchased from high-purity standards (SC, USA).

Analytical grade reagents $\mathrm{HF}, \mathrm{HClO}_{4}, \mathrm{HCl}, \mathrm{HNO}_{3}, \mathrm{NaOH}$, thiocarbamide (Chemreaktivsnab, Russia) were used. Hydrochloric and nitric acids of analytical grade were purified by distillation using distillacid ${ }^{\mathrm{TM}}$ BSB-939-IR (Berghof, Germany). Solutions of lower concentrations were prepared by dilution of concentrated acids with deionized water. Deionized

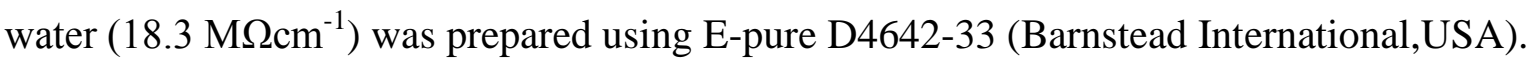

The eluent $(10 \%(\mathrm{w} / \mathrm{w})$ thiocarbamide solution in $1.0 \mathrm{M} \mathrm{HCl})$ was prepared by dissolving a weighed portion of thiocarbamide in $1.0 \mathrm{M} \mathrm{HCl}$. The calibration solutions for ICP-OES and ICP-MS determination of precious metals in eluates were prepared by adding of $0.1-100.0 \mu \mathrm{g}$ of appropriate metal in the eluent.

Silica gel 60 (particle size of $0.10-0.16 \mathrm{~mm}$, specific surface area of $270 \mathrm{~m}^{2} \mathrm{~g}^{-1}$, an average pore size of $\sim 12 \mathrm{~nm}$ ) purchased from Merck (Germany) was used as a matrix for the synthesis of the DTCS.

Ethanol (Chemreaktivsnab, Russia) purified by double distillation, carbon disulfide (puriss. p.a., assay min 99,9\%, Sigma-Aldrich, CAS N.: 75-30-2), and ( $\gamma$ aminopropyl)triethoxysilan (99\%, Sigma-Aldrich, CAS N.: 919-30-2) were used for the DTCS synthesis.

Geological samples and their processing products were: certified reference materials of sulfide copper-nickel ore (VT-1 GSO (state standard sample) no. 929-86), nickel concentrate (KN-1 GSO no. 1702-96), copper-nickelfeinstein (FShT-42 GSO 9315-2009), and matte of orethermal smelting (ShT-1 GSO no. 2432-83) purchased from "Sibtsvetmetniiproekt" (Krasnoyarsk, Russia).

\section{Synthesis of the adsorbent}

DTCS synthesis was carried out in two stages. In the first stage chemical modification of silica gel with aminopropyl groups was carried out by reacting with ( $\gamma$-aminopropyl)triethoxysilane according to a procedure described earlier [17].

Then, $85.0 \mathrm{~g}$ of prepared aminopropyl silica gel was placed in a reactor equipped with a stirrer, $200.0 \mathrm{~mL}$ of absolute ethanol was added and stirred.

Carbon disulfide dissolved in absolute ethanol $\left(7.1 \mathrm{~mL}\right.$ of $\mathrm{CS}_{2}$ in $\left.20.0 \mathrm{~mL} \mathrm{C}_{2} \mathrm{H}_{5} \mathrm{OH}\right)$ and $\mathrm{NaOH}$ solution $(3.5 \mathrm{~g})$ in $70.0 \mathrm{~mL}$ of ethanol were added.

The mixture was stirred for $3 \mathrm{~h}$ at the room temperature. Prepared DTCS was separated from the solution by filtration, three times washed with $50.0 \mathrm{~mL}$ ethanol, placed in to the round 
bottom flask and was evacuated $(15 \mathrm{~mm} \mathrm{Hg})$ at room temperature to remove the excess of carbon disulfide.

Thereafter DTCS was washed for 24 hours in a Soxhlet apparatus with absolute ethanol and dried at $60-70^{\circ} \mathrm{C}$ under vacuum $(15 \mathrm{~mm} \mathrm{Hg})$.

Scheme of the adsorbent synthesis is shown in Figure 1.

\section{Hydrolytic stability of DTCS}

In order to investigate hydrolytic stability of DTCS, weighed portion of the adsorbent was placed in $2.0 \mathrm{M} \mathrm{HCl}$ solution, heated up to $95^{\circ} \mathrm{C}$ and shacked well for $2 \mathrm{~h}$. Every $30 \mathrm{~min}$ an aliquot of the solution was taken and the sulfur content in it was determined by ICP-OES. The sulfur content in the solution is proportional to the quantity of groups that have passed into the solution as a result of the hydrolytic destruction of the grafted surface layer.

\section{Batch procedure}

In the batch experiment $10.0 \mu \mathrm{g}$ of metal ion as a solution in $0.5-4.0 \mathrm{M} \mathrm{HCl}$ was placed into a thermostated test tube; $\mathrm{HCl}$ or $\mathrm{NaOH}$ was added to adjust required acidity; and deionized water was added to a total volume of $10.0 \mathrm{~mL}$. The adsorbent mass of $0.100 \mathrm{~g}$ was added; the tube was stopped and stirred for 1-60 min at 20 and $95^{\circ} \mathrm{C}$. In the study of adsorption of kinetically inert platinum metals at $95^{\circ} \mathrm{C}, 1.0 \mathrm{~mL}$ of a $0.025 \mathrm{M} \mathrm{SnCl}_{2}$ solution was added. The solution was separated from the adsorbent by decantation. For desorption of precious metals, $10.0 \mathrm{~mL}$ of a $10 \%(\mathrm{w} / \mathrm{w})$ solution of thiocarbamide in $1.0 \mathrm{M} \mathrm{HCl}$ was added to the adsorbent and stirred for $1-60 \mathrm{~min}$ at 20 or $95^{\circ} \mathrm{C}$. The distribution of the metal was monitored by the analysis of aqueous phase by ICP-OES.

In order to determine the adsorption capacity of DTCS for precious metals $0.1 \mathrm{~g}$ of the DTCS adsorbent was added to the $10.0 \mathrm{~mL}$ of the solution containing from $1.0 \mu \mathrm{g} \mathrm{mL}^{-1}$ to 10.0 $\mathrm{mg} \mathrm{mL} \mathrm{m}^{-1}$ of the metal in $2.0 \mathrm{M} \mathrm{HCl}$, and stirred for $30 \mathrm{~min}$ at $20^{\circ} \mathrm{C}$ (for $\mathrm{Au}^{3+}, \mathrm{Pd}^{2+}$, and $\mathrm{Pt}^{4+}$ adsorption) or for $60 \mathrm{~min}$ at $95^{\circ} \mathrm{C}$ in the presence of $0.025 \mathrm{M} \mathrm{SnCl}_{2}$ (for $\mathrm{Rh}^{3+}, \mathrm{Ir}^{4+}, \mathrm{Ru}^{4+}$, and $\mathrm{Os}^{4+}$ adsorption).Then the residual metal content in the solution was determined. Quantity of adsorbed metal was calculated as a difference between initial and residual concentration of the metal in the solution.

\section{Column procedure}

To construct a breakthrough curves of platinum metals adsorption, solutions containing 1.0 and $10.0 \mu \mathrm{g} \mathrm{mL}^{-1} \mathrm{Pd}^{2+}$ or $\mathrm{Ir}^{4+}$ was passed through a glass column (i.d. of $3 \mathrm{~mm}$, height of $10 \mathrm{~cm}$ ) 
containing $0.2 \mathrm{~g}$ of DTCS adsorbent with a solution flow rate of 1 and $2.0 \mathrm{~mL} \mathrm{~min}^{-1}$. Adsorption of $\mathrm{Pd}^{2+}$ was carried out at $20^{\circ} \mathrm{C}$, and $\mathrm{Ir}^{4+}$ at $95^{\circ} \mathrm{C}$ in the presence of $0.0025 \mathrm{M} \mathrm{SnCl}_{2}$.

The study of adsorption of the kinetically labile chlorocomplexes of $\mathrm{Au}^{3+}, \mathrm{Pd}^{2+}$, and $\mathrm{Pt}^{4+}$ in the dynamic mode was carried out at $20^{\circ} \mathrm{C}$ passing $10.0,25.0,50.0 \mathrm{~mL}$ of a solution containing $1.0,10.0,50.0 \mu \mathrm{g}$ of a precious metal ion through a column containing $0.2 \mathrm{~g}$ of DTCS adsorbent with a flow rate of $0.5-4.0 \mathrm{~mL} \mathrm{~min}^{-1}$. To elute these precious metals, $10.0 \mathrm{~mL}$ of a $10 \%(\mathrm{w} / \mathrm{w})$ thiocarbamide solution in $1 \mathrm{M} \mathrm{HCl}$ at $20^{\circ} \mathrm{C}$ was passed through the column at a flow rate of $0.5-$ $2.0 \mathrm{~mL} \mathrm{~min}^{-1}$.

The study of adsorption of the kinetically inert chlorocomplexes of $\mathrm{Rh}^{3+}, \mathrm{Ir}^{4+}, \mathrm{Ru}^{4+}$, and $\mathrm{Os}^{4+}$ in the dynamic mode was carried out at $95^{\circ} \mathrm{C}$ passing $10.0,25.0,50.0 \mathrm{~mL}$ of a solution containing 1.0, 10.0, $50.0 \mu \mathrm{g}$ of a precious metal ion and $0,0025 \mathrm{M} \mathrm{SnCl}_{2}$ through a thermostated column containing $0.2 \mathrm{~g}$ of DTCS adsorbent with a flow rate of $0.5-4.0 \mathrm{~mL} \mathrm{~min}^{-1}$. To desorb these precious metals, $10.0 \mathrm{~mL}$ of a $10 \%(\mathrm{w} / \mathrm{w})$ thiocarbamide solution in $1.0 \mathrm{M} \mathrm{HCl}$ at $95^{\circ} \mathrm{C}$ was passed through the column at a flow rate of $0.5-2.0 \mathrm{~mL} \mathrm{~min}^{-1}$.

The separation of kinetically labile chloride complexes of precious metals from kinetically inert ones and their preconcentration was carried out using a system of two successively connected mini-columns (Figure 2) containing $0.2 \mathrm{~g}$ of DTCS adsorbentin each.

\section{Selectivity test}

The study of the selectivity of preconcentration and determination of precious metals was carried out using a single-column system. For this purpose, binary systems containing $10.0 \mu \mathrm{g} \mathrm{Au}{ }^{3+}$ or another precious metal and increasing excess of foreign ions in $25.0 \mathrm{~mL}$ of $2.0 \mathrm{M} \mathrm{HCl}$ were prepared. When studying the selectivity of preconcentration and determination of $\mathrm{Au}^{3+}, \mathrm{Pd}^{2+}$, $\mathrm{Pt}^{4+}$, the solutions were passed through a column at $20^{\circ} \mathrm{C}$ with a flow rate of $1.0 \mathrm{~mL} \mathrm{~min}{ }^{-1}$. After SPE, $20.0 \mathrm{~mL}$ of $2.0 \mathrm{M} \mathrm{HCl}$ was passed through the column to remove retained non-ferrous metal ions and $10.0 \mathrm{~mL}$ of a $10 \%(\mathrm{w} / \mathrm{w})$ thiocarbamide solution in $1.0 \mathrm{M} \mathrm{HCl}$ to elute the precious metal. The study of the selectivity of preconcentration and determination of $\mathrm{Ru}^{4+}, \mathrm{Os}^{4+}$, $\mathrm{Ir}^{4+}$, and $\mathrm{Rh}^{3+}$ in the dynamic mode was carried out at $95^{\circ} \mathrm{C}$ in the presence of $\mathrm{SnCl}_{2}$. Then, 20.0 $\mathrm{mL}$ of $2.0 \mathrm{M} \mathrm{HCl}$ was passed through the column to remove retained non-ferrous metal ions and $\mathrm{SnCl}_{2}$. Elution of $\mathrm{Ru}^{4+}, \mathrm{Os}^{4+}, \mathrm{Ir}^{4+}$, and $\mathrm{Rh}^{3+}$ was carried out at $95^{\circ} \mathrm{C}$ by pumping of $10.0 \mathrm{~mL}$ of a $10 \%(\mathrm{w} / \mathrm{w})$ thiocarbamide solution in $1.0 \mathrm{M} \mathrm{HCl}$. Effect of each ion was considered to be interfering if the amount of precious metal found changed more than $\pm 5 \%$.

\section{Sample preparation}


Geological samples contain a significant quantity of sulfides, so a pre-dried (at $105^{\circ} \mathrm{C}$ ) sample portions of $2.0000 \mathrm{~g}$ before digestion were roasted in a muffle furnace for $2 \mathrm{~h}$ at $500^{\circ} \mathrm{C}$. A roasted sample portion was placed into a glassy carbon crucible, moistened with deionized water, then $25.0 \mathrm{~mL}$ conc. $\mathrm{HF}$ and $2.0 \mathrm{~mL} \mathrm{H}_{2} \mathrm{SO}_{4}$ (diluted 1:1) were added. The digestion was carried out under slow heating until sulfuric anhydride vapors appeared. Then, $30.0 \mathrm{~mL}$ mixture of acids $\mathrm{HF}$ : $\mathrm{HClO}_{4}: \mathrm{HCl}: \mathrm{HNO}_{3}(2: 2: 3: 3)$ was added; the digestion was carried out under heating, and mixture of acids was evaporated to dryness. Then, $30.0 \mathrm{~mL}$ mixture of acids $\mathrm{HCl}: \mathrm{HNO}_{3}(3: 1)$ was added to sample and evaporated to wet salts. $10.0 \mathrm{~mL}$ of concentrated $\mathrm{HCl}$ was added to the residue and evaporated to wet salts; the procedure was repeated twice. Afterwards, $20.0 \mathrm{~mL}$ of concentrated $\mathrm{HCl}$ and $20.0 \mathrm{~mL}$ of deionized water was added, and salts were dissolved under heating. The solution was transferred into a $100 \mathrm{~mL}$ volumetric flask and diluted with $2.0 \mathrm{M} \mathrm{HCl}$ to the mark.

\section{Calculations}

The extraction efficiency $(\mathrm{R}, \%)$ of metal ions extracted by DTCS was determined as follows:

$R=\left[\left(C_{0}-C\right) / C_{0}\right] \cdot 100 \%$

$C_{0}$-initial metal concentration in the solution, $\mathrm{mmol} \mathrm{L}^{-1}$,

$C$-equilibrium metal concentration in the solution, $\mathrm{mmol} \mathrm{L}^{-1}$.

The elution efficiency $\left(R_{e l}, \%\right)$ was determined as follows:

$R_{e l}=\left[C_{e l} /\left(C_{0}-C\right)\right] \cdot 100 \%$

$C_{e l}-$ metal concentration in the effluent, $\mathrm{mmol} \mathrm{L}^{-1}$,

The quantity of metal ions extracted $\left(q, \mathrm{mmol} \mathrm{g}^{-1}\right)$ by DTCS was calculated from Eq.(3):

$q=\left[\left(C_{0}-C\right) \cdot V\right] / m$

$V$ - the solution volume, L,

$m$-the mass of TCS, $\mathrm{g}$.

\section{Results and discussion}

\section{Characterization of DTCS}

Surface concentration of fixed functional groups according to elemental analysis data was $0.16 \pm 0.01 \mathrm{mmol} \mathrm{g}^{-1}$.

Dehydration occurred during heating of DTCS to $150^{\circ} \mathrm{C}$ which causes mass reduction of $4.6 \%$ (Figure 3). Upon further heating of the sample up to $250-330^{\circ} \mathrm{C}$, NCS release took place due to decomposition of dithiocarbaminate groups. $\mathrm{CO}, \mathrm{CO}_{2}, \mathrm{NH}_{3}, \mathrm{HCN}, \mathrm{H}_{2} \mathrm{O}, \mathrm{SO}_{2}$ were released at $300-450^{\circ} \mathrm{C}$ (Figure 4). Decomposition of propyl groups accompanied by the release of $\mathrm{CO}_{2}$ was observed at $350-650^{\circ} \mathrm{C}$. A mass loss of $2.3 \%$ when heated from $200^{\circ} \mathrm{C}$ to $400^{\circ} \mathrm{C}$ 
correlated with the content of grafted dithiocarbamate groups on the adsorbent surface- $2.2 \%$. The second peak of $\mathrm{H}_{2} \mathrm{O}$ release at $300-450^{\circ} \mathrm{C}$ was associated with the conversion of silanol groups to siloxane with the elimination of water molecule.

The functional groups of the DTKS adsorbent were thermally stable up to a temperature of $150^{\circ} \mathrm{C}$. The adsorption of chlorocomplexes of kinetically inert platinum group metals by silica gels chemically modified with sulfur-containing groups, in particular mercaptopropyl groups and thiourea derivative groups, was achieved from solutions of hydrochloric acid (1.0-3.0 M) and at elevated temperature $\left(95^{\circ} \mathrm{C}\right)$ for a long phase contact time $(30-40 \mathrm{~min})$ [18, 19]. Long heating the adsorbents in $\mathrm{HCl}$ solutions can lead to the destruction of the grafted surface layer. As can be seen from Table 3, heating the adsorbent in $2.0 \mathrm{M} \mathrm{HCl}$ for $1.5 \mathrm{~h}$ does not lead to the destruction of the grafted groups. Therefore, it can be concluded that the adsorbents are sufficiently hydrolytically stable for the time required for adsorption of kinetically inert platinum group metals from 2.0 M HCl. An increase in the contact time of the adsorbent with a solution of $2.0 \mathrm{M}$ $\mathrm{HCl}$ to $2 \mathrm{~h}$ leads to the destruction of $30 \%$ of the surface functional groups.

Figure 5 shows the FT-IR characterization of DTCS adsorbent. The band near $1630 \mathrm{~cm}^{-1}$ corresponds to the bending mod of $\mathrm{OH}$ groups of adsorbed water and the broad band at $3400 \mathrm{~cm}^{-}$ ${ }^{1}$ assigned to adsorbed water and $\mathrm{H}$ bonded silanol $\mathrm{OH}$ groups. Low intensity band at $2890 \mathrm{~cm}^{-1}$ assigned to $\mathrm{CH}$ stretching modes of propyl group attached to the $\mathrm{Si}-\mathrm{O}$ surface. In the IR spectrum of the DTCS adsorbent, a series of medium and low intensity bands are observed, which are also observed in the IR spectrum of sodium N,N'-diethyldithiocarbamate [20]. The low intensity band at $1465 \mathrm{~cm}^{-1}$ is attributed to the deformational vibrations $v_{\mathrm{as}}\left(\mathrm{NCS}_{2}\right)$, and the band at $1504 \mathrm{~cm}^{-1}$ is attributed to the stretching vibrations of the $\mathrm{C}-\mathrm{S}$ bond.

As the temperature rises, the dithiocarbamate groups, attached to the silica surface, decompose with NCS release (Figure 4). In the IR spectrum of the gas phase for the compound $\mathrm{N}=\mathrm{C}=\mathrm{S}$, an intense band of stretching asymmetric vibrations is observed at $2200-2050 \mathrm{~cm}^{-1}$. Based on this, low-intensity bands at 2200 and $2100 \mathrm{~cm}^{-1}$ in the IR spectrum of the adsorbent can be attributed to asymmetric vibrations $v_{\text {as }}(\mathrm{NCS})$.

\section{Effect of $\mathrm{pH}$ and $\mathrm{HCl}$ concentration}

The content of gold and platinum group metals in geological objects is low. The main macrocomponents of geological materials are $\mathrm{Na}, \mathrm{K}, \mathrm{Ca}, \mathrm{Mg}, \mathrm{Al}, \mathrm{Si}$, and $\mathrm{Fe} . \mathrm{Cu}, \mathrm{Ni}, \mathrm{Co}, \mathrm{Cd}, \mathrm{Pb}$, and Mn are also present in lower concentrations. To determine the possibility of selective extraction of precious metal ions from non-ferrous metals, the dependences of adsorption of non-ferrous metal ions vs. $\mathrm{HCl}$ concentration and $\mathrm{pH}$ was studied. 
As can be seen from Figure 6, the maximum extraction of non-ferrous metal ions by DTCS adsorbent achieved in the range of $\mathrm{pH} 3-8$. Alkaline and alkaline-earth elements are not extracted by DTKS in the range from $4.0 \mathrm{M} \mathrm{HCl}$ to $\mathrm{pH}$ 8. There is no adsorption of non-ferrous metals from 1.0-4.0 M HCl solutions, which allows separation of platinum group metals and gold from the prevailing amounts of related metals in the media of 1.0-4.0 M HCl. Most sample preparation techniques for geological and technological samples containing precious metals, include transfer to 1.0 or $2.0 \mathrm{M} \mathrm{HCl}$ media after oxidative digestion. The resulting solutions after digestion contain chloride complexes of precious metals of following oxidation degree: $\mathrm{Pd}-2+$, $\mathrm{Au}, \mathrm{Rh}-3+, \mathrm{Pt}, \mathrm{Ir}, \mathrm{Ru}-4+$. Platinum group metals in acidic solutions form with sulfurcontaining groups significantly more stable complexes than the non-ferrous and other related metals.Non-ferrous metal ions, tend to form insoluble sulfides, react with sulfur-containing groups in weakly acidic, neutral or weakly alkaline solutions; significant adsorption (about $80 \%$ ) in the range of 1.0-4.0 M HCl was observed only for $\mathrm{Cu}^{2+}$.

DTCS adsorbent quantitatively (extraction $\geq 98 \%$ ) extracted $\mathrm{Au}^{3+}, \mathrm{Pd}^{2+}$, and $\mathrm{Pt}^{4+}$ from $0.5-$ 4.0 $\mathrm{M} \mathrm{HCl}, \mathrm{Ag}^{+}$was not extracted from 1.0-4.0 M HCl. The time of attainment of adsorption equilibrium was $5 \mathrm{~min}$ for $\mathrm{Au}^{3+}$ and $\mathrm{Pd}^{2+}$, and $20 \mathrm{~min}$ for $\mathrm{Pt}^{4+}$.

$\mathrm{Rh}^{3+}, \mathrm{Ir}^{4+}, \mathrm{Ru}^{4+}$, and $\mathrm{Os}^{4+}$ chloride complexes are kinetically inert in ligand substitution reactions [21, 22], so, they were not extracted by DTCS adsorbent at room temperature in the range of 1.0-4.0 M HCl even after the long phase contact time (60 min) (Table 4). Increasing the temperature up to $95^{\circ} \mathrm{C}$ as well as increasing the phase contact time also does not lead to their quantitative extraction. Extraction of $\mathrm{Rh}^{3+}, \mathrm{Ir}^{4+}, \mathrm{Ru}^{4+}$, and $\mathrm{Os}^{4+}$ at $95^{\circ} \mathrm{C}$ does not exceed $50 \%$ (Table 4).

So, preconcentration of $\mathrm{Au}^{3+}$ and platinum group metals from 1.0-4.0 M HCl allows their separation from the predominant amounts of alkali, alkaline-earth, non-ferrous and some other metals. During adsorption at room temperature, a quantitative separation of kinetically labile platinum group metals $\left(\mathrm{Au}^{3+}, \mathrm{Pd}^{2+}\right.$, and $\left.\mathrm{Pt}^{4+}\right)$ from kinetically inert ones $\left(\mathrm{Rh}^{3+}, \mathrm{Ir}^{4+}, \mathrm{Ru}^{4+}\right.$, and $\mathrm{Os}^{4+}$ ) was achieved.

The adsorption capacity of DTCS for $\mathrm{Au}^{3+}, \mathrm{Pd}^{2+}, \mathrm{Pt}^{4+}, \mathrm{Rh}^{3+}, \mathrm{Ir}^{4+}, \mathrm{Ru}^{4+}$, and $\mathrm{Os}^{4+}$ determined from the horizontal sections of adsorption isotherms is represented in Table 5.

\section{Column experiment}

Breakthrough curves of precious metals by the example of the kinetically labile chlorocomplex $\mathrm{Pd}^{2+}$ and the kinetically inert chlorocomplex $\mathrm{Ir}^{4+}$ are represented in Figure 7. As can be seen from Figure 7 an increase in the solution flow rate from 1.0 to $2.0 \mathrm{~mL} \mathrm{~min}^{-1}$ does not significantly affect the extraction of platinum metals in a dynamic mode. 
Studies of adsorption and elution at $20^{\circ} \mathrm{C}$ in a dynamic mode showed that quantitative extraction of 1.0, 10.0 and $50.0 \mu \mathrm{g} \mathrm{Au} \mathrm{Au}^{3+}, \mathrm{Pd}^{2+}, \mathrm{Pt}^{4+}$ was achieved at a flow rate of $\leq 2.0 \mathrm{~mL} \mathrm{~min}{ }^{-1}$. A change in the volume of the solution from 10.0 to $50.0 \mathrm{~mL}$ did not affect the extraction of precious metals. Under these conditions, $\mathrm{Rh}^{3+}, \mathrm{Ir}^{4+}, \mathrm{Ru}^{4+}, \mathrm{Os}^{4+}$ were not retained by the adsorbent and passed through the column. Adsorbed $\mathrm{Au}^{3+}, \mathrm{Pd}^{2+}, \mathrm{Pt}^{4+}$ were desorbed with $10.0 \mathrm{~mL}$ of a $10 \%(\mathrm{w} / \mathrm{w})$ thiocarbamide solution in $1.0 \mathrm{M} \mathrm{HCl}$ at $20^{\circ} \mathrm{C}$ at a solution flow rate of $0.5 \mathrm{~mL} \mathrm{~min}{ }^{-1}$.

Quantitative extraction of $1.0,10.0$ and $50.0 \mu \mathrm{g}$ of $\mathrm{Rh}^{3+}, \mathrm{Ir}^{4+}, \mathrm{Ru}^{4+}, \mathrm{Os}^{4+}$ by DTCS adsorbent was achieved from $10.0-50.0 \mathrm{~mL}$ of solution at $95^{\circ} \mathrm{C}$ in the presence of $\mathrm{SnCl}_{2}$ at a solution flow rate of $\leq 2.0 \mathrm{~mL} \mathrm{m^{-1 }}$. Quantitative elution of which was achieved by passing through a column at $95^{\circ} \mathrm{C}$ of $10.0 \mathrm{~mL}$ of a $10 \%(\mathrm{w} / \mathrm{w})$ thiocarbamide solution in $1.0 \mathrm{M} \mathrm{HCl}$ at a flow rate of $0.5 \mathrm{~mL} \mathrm{~min}^{-1}$.

Table 6 shows data on the extraction of platinum metals and gold from $2.0 \mathrm{M} \mathrm{HCl}$. As can be seen from the table, the use of DTCS adsorbent allows separation of the kinetically labile chlorocomplexes of $\mathrm{Au}^{3+}, \mathrm{Pd}^{2+}, \mathrm{Pt}^{4+}$ from the kinetically inert chlorocomplexes $\mathrm{Rh}^{3+}, \mathrm{Ir}^{4+}, \mathrm{Ru}^{4+}$, $\mathrm{Os}^{4+}$ in a dynamic mode.

\section{Effect of foreign ions}

For selectivity test, the effect of the accompanying ions $\left(\mathrm{Na}^{+}, \mathrm{K}^{+}, \mathrm{Ca}^{2+}, \mathrm{Mg}^{2+}, \mathrm{Fe}^{3+}, \mathrm{Al}^{3+}, \mathrm{Cu}^{2+}\right.$, $\mathrm{Pb}^{2+}, \mathrm{Zn}^{2+}, \mathrm{Mn}^{2+}, \mathrm{Ni}^{2+}, \mathrm{Co}^{2+}$, and $\left.\mathrm{Fe}^{2+}\right)-$ the main components of geological materials on the SPE of precious metals by DTCS was investigated at 20 and $95^{\circ} \mathrm{C}$. The effect of each ion was considered to be interfering if the amount of precious metal found changed more than $\pm 5 \%$. SPE of $\mathrm{Au}^{3+}, \mathrm{Pd}^{2+}, \mathrm{Pt}^{4+}, \mathrm{Ru}^{4+}, \mathrm{Os}^{4+}, \mathrm{Ir}^{4+}$, and $\mathrm{Rh}^{3+}$ was not affected by $10^{6}$-fold excess of alkaline, alkaline-earth and $10^{4}$-fold excess of non-ferrous metals and iron that are not extracted from 2.0 $\mathrm{M} \mathrm{HCl}$ by DTCS.

Despite the fact that extraction of $\mathrm{Cu}^{2+}$ from $2.0 \mathrm{M} \mathrm{HCl}$ reaches $80 \%$ (Figure 6), its 1000fold excess did not affect SPE of precious metals. After passing through the column of solutions containing $\mathrm{Pd}^{2+}$ and $\mathrm{Cu}^{2+}$, the toplayer of the adsorbent was colored brown, corresponding to the color of the complex of $\mathrm{Pd}^{2+}$ with dithiocarbamate groups, and the entire surface of the adsorbent in the column was colored yellow-green, corresponding to adsorbed copper. After subsequent passing of $20.0 \mathrm{~mL}$ of $2.0 \mathrm{M} \mathrm{HCl}$ through the column, the yellow-green color of the adsorbent disappearedas a result of copper desorption, but the zone corresponding to the $\mathrm{Pd}^{2+}$ complex remained unchanged. Subsequent passing of a $10 \%(\mathrm{w} / \mathrm{w})$ thiocarbamide solution in $1.0 \mathrm{M} \mathrm{HCl}$, led to desorption of $\mathrm{Pd}^{2+}$ into the solution, and the adsorbent discolored.

Separation of precious metals from non-ferrous and other metals eliminates the effect on their determination in desorbing solutions of polyatomic ions of accompanying elements, for 
example ${ }^{63} \mathrm{Cu}^{40} \mathrm{Ar}$ on the determination of ${ }^{103} \mathrm{Rh}$,or ${ }^{61} \mathrm{Ni}^{40} \mathrm{Ar}$ and ${ }^{64} \mathrm{Zn}^{37} \mathrm{Cl}$ on the definition of ${ }^{101} \mathrm{Ru}$.

\section{Analysis of Geological Samples}

As studies have shown, kinetically labile chlorocomplexes of platinum group metals $\left(\mathrm{Pd}^{2+}, \mathrm{Pt}^{4+}\right)$ and $\mathrm{Au}^{3+}$ are extracted with DTCS adsorbent in batch and dynamic modes at room temperature, and kinetically inert ones $\left(\mathrm{Rh}^{3+}, \mathrm{Ir}^{4+}, \mathrm{Ru}^{4+}, \mathrm{Os}^{4+}\right)$ only at $95^{\circ} \mathrm{C}$ and in the presence of labilizing agent $\mathrm{SnCl}_{2}$. This difference made it possible to use a system of two successively connected mini-columns (Figure 2) containing DTCS adsorbent to separate kinetically labile chlorocomplexes of precious metals from kinetically inert ones in a dynamic mode and their determination in geological materials.

For this, the solution $(25.0 \mathrm{~mL})$ after the decomposition of geological material was pumped through a system of two mini-columns (Figure 2) containing $0.2 \mathrm{~g}$ of DTCS adsorbent with the flow rate of $1.0 \mathrm{~mL} \min ^{-1}$. On the first column (1) at $20^{\circ} \mathrm{C}$, the kinetically labile chlorocomplexes $\mathrm{Au}^{3+}, \mathrm{Pd}^{2+}, \mathrm{Pt}^{4+}$ were retained. $\mathrm{SnCl}_{2}$ solution was added in the stream after the first column (1) at $20^{\circ} \mathrm{C}$ by means of tap (2) with the flow rate of $1.0 \mathrm{~mL} \mathrm{~min}^{-1}$. Then, the solution was passed through the second thermostated column (3) at $95^{\circ} \mathrm{C}$. On the second column, adsorption of kinetically inert complexes of $\mathrm{Rh}^{3+}, \mathrm{Ir}^{4+}, \mathrm{Ru}^{4+}, \mathrm{Os}^{4+}$ occurred. Then, $20.0 \mathrm{~mL}$ of 2.0 $\mathrm{M} \mathrm{HCl}$ was pumped through two-column system in order to remove retained non-ferrous metals and $\mathrm{SnCl}_{2}$. This approach of separate preconcentration of precious metals allows their separate elution from the columns. For elution of $\mathrm{Au}^{3+}, \mathrm{Pd}^{2+}, \mathrm{Pt}^{4+}, 10.0 \mathrm{~mL} 10 \%(\mathrm{w} / \mathrm{w})$ thiocarbamide solution in $1.0 \mathrm{M} \mathrm{HCl}$ was passed through the first column at $20^{\circ} \mathrm{C}$ with a flow rate of $1.0 \mathrm{~mL}$ $\mathrm{min}^{-1}$. For desorption of $\mathrm{Rh}^{3+}, \mathrm{Ir}^{4+}, \mathrm{Ru}^{4+}, \mathrm{Os}^{4+}, 10.0 \mathrm{~mL} 10 \%(\mathrm{w} / \mathrm{w})$ thiocarbamide solution in 1.0 $\mathrm{M} \mathrm{HCl}$ was pumped through the second column at a flow rate of $1.0 \mathrm{~mL} \mathrm{~min}{ }^{-1}$ at $95^{\circ} \mathrm{C}$.

Precious metals were determined in the effluents using ICP-OES and ICP-MS. The calibration standards were prepared using eluent as a matrix. The limits of detection of precious metals in thiocarbamide solutions calculated by the 3s-criterion are given in Table 7.

If the concentration of precious metal in the effluent was $\leq 0.005 \mu \mathrm{g} \mathrm{mL}{ }^{-1}$, the determination was carried out by the ICP-MS, and if the concentration was $\geq 0.005 \mu \mathrm{g} \mathrm{mL}^{-1}$ the determination was carried out by the ICP-OES.

Results of analysis of certified reference materials of ore and its processing products are represented in Table 8 .

\section{Conclusion}


Silica gel chemically modified with dithiocarbamate groups allows separation of precious metals from prevailing amounts of alkali, alkaline-earth, non-ferrous and other related metals. The adjustment of the adsorption parameters allows separation of kinetically labile and kinetic inert precious metals using one adsorbent - DTCS: during adsorption at $20^{\circ} \mathrm{C}$ DTCS selectively extracted $\mathrm{Au}^{3+}, \mathrm{Pd}^{2+}$, and $\mathrm{Pt}^{4+}$, and during adsorption at $95^{\circ} \mathrm{C}$ in the presence of $\mathrm{SnCl}_{2}$ it extracted $\mathrm{Rh}^{3+}, \mathrm{Ir}^{4+}, \mathrm{Ru}^{4+}$, and $\mathrm{Os}^{4+}$.

Two-column procedure allows the use of different methods for the determination of precious metals in the efflunts. Because the content of $\mathrm{Au}, \mathrm{Pd}$, and $\mathrm{Pt}$ in geological samples and their processing products significantly exceeds the content of $\mathrm{Rh}, \mathrm{Ir}, \mathrm{Ru}$, and Os. Thus, the determination of $\mathrm{Au}, \mathrm{Pd}$, and $\mathrm{Pt}$ in the effluent from the first column can be carried out using ICP-AES or FAAS, and low contents of $\mathrm{Rh}, \mathrm{Ir}, \mathrm{Ru}$, and Os in the effluent from the second column can be determined using more sensitive methods such as ICP-MS or ETA-AAS.

Comparison of the results of determination of gold and platinum metals in certified reference materials with certified values shows that the proposed procedure allows obtaining correct and reproducible results.

\section{Funding}

This work was supported by the Ministry of Education and Science of the Russian Federation under Grant no. 4.6343.2017 for Siberian Federal University.

\section{References}

1. Mladenova, E., Karadjova, I., Tsalev, D. L. (2012). Solid-phase extraction in the determination of gold, palladium, and platinum. Journal of Separation Science, 35(10-11), 1249-1265. doi:10.1002/jssc.201100885

2. Godlewska-Zyłkiewicz, B. (2004). Preconcentration and separation procedures for the spectrochemical determination of platinum and palladium. Microchimica Acta, 147(4), 189-210. doi:10.1007/s00604-004-0234-2

3. Mokhodoeva O.B., Myasoedova G.V., Kubrakova I.V. Sorption preconcentration in combined methods for the determination of noble metals // J. of Anal. Chem.. 2007. V. 62. № 7. P. 607 622 .

4. Myasoedova G.V., Mokhodoeva O.B., Kubrakova I.V. Trends in sorption preconcentration combined with noble metal determination // Anal. Science. 2007. V. 23. P. 1031 - 1039.

5. Pyrzynska, K. (2012). Sorbent materials for separation and preconcentration of gold in environmental and geological samples - A review. Analytica Chimica Acta, 741, 9-14. doi:10.1016/j.aca.2012.06.044 
6. Fedyunina, N. N., Seregina, I. F., Ossipov, K., Dubenskiy, A. S., Tsysin, G. I., \& Bolshov, M. A. (2013). Specificity of noble metals dynamic sorption preconcentration on reversed-phase sorbents. Analytica Chimica Acta, 798, 109-114. doi:10.1016/j.aca.2013.08.049

7. Schilling T., Schramel P., Michalke B., Knapp G. Separation of noble metal ions with chemically bonded ligands //Microchim Acta. 1994. V. 116. P. 83-90.

8. Jal P.K., Patel S., Mishra B.K. Chemical modification of silica surface by immobilization of functional groups for extractive concentration of metal ions // Talanta. 2004. V. 62. P. 1005 1028.

9. Zougagh M., Cano Pavon J.M., Garcia de Torres A. Chelating sorbents based on silica gel and their application in atomic spectrometry // Anal. Bioanal. Chem. 2005. V. 381. P. $1103-1113$.

10. Abughudsa A., Amaratunga L., Mercier L. Extraction of precious metal ions simulated mine effluents using nanostructured adsorbent//Canadian Metallurgical Guarternary. 2006. V. 45. № 3. P. 237-242.

11. Li, Y., Huang, Y. -., Jiang, Y., Tian, B. -., Han, F., \& Yan, X. -. (2011). Displacement solidphase extraction on mercapto-functionalized magnetite microspheres for inductively coupled plasma mass spectrometric determination of trace noble metals. Analytica Chimica Acta, 692(12), 42-49. doi:10.1016/j.aca.2011.02.055

12. Losev, V. N., Borodina, E. V., Buiko, O. V., Maznyak, N. V., \& Trofimchuk, A. K. (2014). Sorption-spectrometric determination of palladium and gold using silica chemically modified with dipropyl disulfide groups. Journal of Analytical Chemistry, 69(5), 413-419. doi:10.1134/S1061934814030101

13. Liu, P., Pu, Q., Hu, Z., \& Su, Z. (2000). On-line preconcentration and separation of platinum using thiourea modified silica gel with microwave assisted desorption for FAAS determination. Analyst, 125(6), 1205-1209. doi:10.1039/b000729n

14. Liu, P., Su, Z., Wu, X., \& Pu, Q. (2002). Application of isodiphenylthiourea immobilized silica gel to flow injection on-line microcolumn preconcentration and separation coupled with flame atomic absorption spectrometry for interference-free determination of trace silver, gold, palladium and platinum in geological and metallurgical samples. Journal of Analytical Atomic Spectrometry, 17(2), 125-130. doi:10.1039/b109628a

15. Star J., Kratzer, K. (1968) Determination of extraction constants of metal diethyldithiocarbamates (Article) Analytica Chimica Acta40(C), 93-100.

16. Chung, Y. S., \& Barnes, R. M. (1988). Determination of gold, platinum, palladium and silver in geological samples by inductively coupled plasma atomic emission spectrometry after poly(dithiocarbamate) resin pre-treatment. Journal of Analytical Atomic Spectrometry, 3(8), 1079-1082. 
17. Venkatesan, K. A., Srinivasan, T. G., \& Vasudeva Rao, P. R. (2001). Cobalt-extraction studies on dithiocarbamate grafted on silica gel surface.Colloids and Surfaces A: Physicochemical and Engineering Aspects, 180(3), 277-284.

18. Losev, V. N., Bakhtina, M. P., \& Komozin, P. N. (1999). Sorption of ruthenium on silica modified with thiourea derivatives.Russian Journal of Inorganic Chemistry, 44(11), 1837-1840.

19. Losev, V. N., Bakhtina, M. P., Kudrina, Y. V., Trofimchuk, A. K., \& Komozin, P. N. (2005). Sorption of osmium and ruthenium in various oxidation states by silica chemically modified with N-(2,6-dimethyl-4-methylenetriphenylphosphonium chloride)phenyl-N'-propylthiourea groups.Russian Journal of Inorganic Chemistry, 50(5), 705-710.

20. Mahmoud, M. E. (1999). Selective solid phase extraction of mercury(II) by silica gelimmobilized-dithiocarbamate derivatives.Analytica Chimica Acta, 398(2-3), 297-304.

21. Buslaeva, T. M., \& Simanova, S. A. (2000). State of the platinum metals in hydrochloric acid and chloride aqueous solutions: Ruthenium and osmium.Russian Journal of Coordination Chemistry/Koordinatsionnaya Khimiya, 26(6), 379-387.

22. Buslaeva, T. M., \& Simanova, S. A. (1999). Platinum metals in aqueous hydrochloric and chloride solutions. palladium, platinum, rhodium, and iridium.Koordinatsionnaya Khimiya, 25(3-4), 165-176.

23. Maria Balcerzak, Stanislaw Kus. Determination of Ruthenium and Osmium with Tin(II) Chloride by Second-Order Derivative Spectrophotometry. Analytical Sciences. FEBRUARY 1994, VOL. 10. P. 65-69.

24. Karim f. G. Brackenbury, lynn jones, iris nel, klaus r. Koch*, jean m. Wiley-birch. Tin(II) chloride in the analytical chemistry of the platinum metals: from the "purple of cassius" to polyurethane foams. Polyhedron vol. 6, no. I, pp. 71-78, 1987.

25. Lynn Jones, Iris Nel, Klaus R. Koch. Polyurethane foams as selective sorbents for noble metals. Quantitative Extraction and Separation of Rhodium from Iridium in Hydrochloric Acid containing Tin( II) Chloride. Analytica Chimica Acta, 182 (1986) P.61-70 